\title{
Presentación del dossier "Mujeres investigando en el Archivo INET"
}

\author{
Laura Mogliani \\ Directora del Instituto Nacional de Estudios de Teatro, Argentina
}

Fecha de recepción: 30/08/2021. Fecha de aceptación: 27/09/2021

Este dossier compila las presentaciones realizadas en el ciclo de charlas virtuales "Mujeres investigando en el archivo INET", que se llevó a cabo entre abril y julio de 2021, organizado por el Instituto Nacional de Estudios de Teatro - INET. Este ciclo propuso difundir las investigaciones realizadas en la institutción en el marco de las distintas becas de investigación otorgadas por el Ministerio de Cultura, tanto las denominadas Investiga Cultura, asignadas en 2019, como las becas Activar Patrimonio, de 2020. No dejó de llamarnos la atención que todas las beneficiarias de estas becas fueran mujeres, y por eso se denominó así al ciclo, con el propósito de destacar el vínculo existente entre las mujeres y el trabajo de archivo, en este caso público, en consonancia con lo planteado por Beatriz Trastoy en relación a las mujeres y los archivos privados, quien destaca que son ellas las responsables de la conformación de los archivos familiares, de las donaciones de esos archivos particulares a instituciones , ya que se erigen en custodias y defensoras de la memoria familiar. (cfr. La Escena Posdramática. Ensayos sobre la autorreferencialidad, 2017: 254-255).

Las mujeres que se dedicaron a investigar en el Archivo del INET se caracterizan por su formación multidisciplinaria, lo que le da gran riqueza y variedad a los trabajos incluidos en este dossier. Lía Noguera es investigadora dedicada a la historia del teatro argentino; Malena Graciosi es música abocada a la investigación en sonido escénico; Laura Gómez Gauna es conservadora especializada en documentos audiovisuales y Camila Losada es antropóloga focalizada en los estudios de género y de circo, además de artista circense. Sus trabajos, con enfoques tan diversos, encuentran líneas de confluencia y puntos en común y constituyen un valiosísimo aporte al resignificar y visibilizar el acervo documental del INET.

Lía Noguera obtuvo la beca Investiga Cultura en 2019 con el proyecto de investigación sobre "La familia Podestá y el Fondo documental Jacobo de Diego (INET): un estudio acerca de las compañías teatrales argentinas, sus asociaciones, vínculos laborales y afectivos". La gran relevancia de su trabajo para el INET es que permite visibilizar la significativa riqueza documental de la donación del importante crítico e investigador teatral. En su estudio sobre las por ella denominadas "compañías- familias", se abocaó inicialmente a la compañía fundacional de José "Pepe" Podestá; luego continuócon la de su hermano Jerónimo Podestá y, en el artículo que se incluye en este dossier, se focaliza en la compañía encabezada Blanca Podestá (hija de Jerónimo), junto con su 
marido, Alberto Ballerini. El novedoso aporte de Lía Noguera en su artículo "Matrimonios y algo más. Blanca Podestá y Alberto Ballerini en clave artística, afectiva y laboral" consiste en agregar el aspecto afectivo al estudio del funcionamiento de las compañías teatrales, al afirmar que el estudio de lo afectivo se constituye en una nueva forma de acceder a los documentos del pasado teatral argentino que permite comprender las lógicas de funcionamiento económico, laboral y artístico de las compañías teatrales de la primera mitad del siglo XX.

En el artículo "Músicas escénicas en el Archivo INET", Malena Graciosi presenta los resultados obtenidos en el desarrollo de su proyecto de investigación, que obtuvo la Beca Activar Patrimonio en 2020. Con su trabajo sobre diversos tipos de documentos del acervo del INET (partituras, documentos textuales y sonoros), Malena Graciosi permitió dar a conocer parte del patrimonio musical del INET y escuchar, gracias a su digitalización, algunas de las partituras que integran su colección. Gracias a su creativa propuesta, es posible acceder a la música de obras paradigmáticas del teatro argentino, como el estilo que compuso y cantaba Pablo Podestá en La piedra de escándalo (1902) de Martín Coronado; la música del sainete Gabino el mayoral (1898) de Enrique García Velloso; el pericón Por María (1900), compuesto por Antonio Podestá en honor a María Podestá, o la que el mismo Antonio compuso para la puesta de Calandria (1896) de Martiniano Leguizamón. Además, el gran aporte del trabajo de Graciosi es focalizarse en un campo de estudio casi vacante, el de la música escénica, que cruza el estudio del vínculo de dos artes, la música y el teatro, con sus similitudes y diferencias. Así, la investigadaora define la composición musical con propósitos escénicos como un arte específico que a nivel profesional requiere conocimientos y aptitudes musicales, pero también, y en igual medida, dramáticas y espectaculares. Lo mismo sucede con la investigación sobre la música escénica, implica el conocimiento de la teoría y la historia de esos dos campos específicos de estudio: el teatro y la música.

Laura Gómez Gauna presenta en su artículo “Un nitrato argentino: El Pericón Nacional. (c. 1906). Documentar para la construcción de una identidad nacional" los resultados de su proyecto de investigación, que también mereció la beca Activar Patrimonio en 2020. El gran aporte de este proyecto fue que en el marco del mismo se realizó la digitalización del film silente Pericón Nacional. (c. 1906), patrimonio del Archivo Audiovisual del INET, lo que permitió visualizarlo y exhibirlo en el ciclo de charlas ya mencionado. Este film es de un valor fundamental tanto para la historia del teatro como del cine y la danza nacional, ya que, por desde el punto de vista escénico presenta la danza del pericón nacional, incorporada en 1889 a las representaciones de Juan Moreira, de la compañía Podestá, en la que se destaca la presencia del personaje de Cocoliche, incluido en la misma puesta desde 1891 . Desde el punto de vista cinematográfico, es un antecedente de los films de ficción, cuyo inicio se establece en el cine argentino con La Revolución de Mayo de Mario Gallo. Además, también es una fuente relevante para el estudio del pericón, danza folklórica nacional, ya que presenta los diferentes cuadros que conforman su coreografía. Otro de los aspectos destacados de este estudio es el de poder datar el mencionado film y conocer su contexto de producción, ya que en el INET no constaba dicha información. Por otra parte, en los primeros años de la cinematografía nacional, hubo varias versiones de films que presentaban el pericón, e inclusive con el mismo nombre, por lo que su reconocimiento inicial resultaba dudoso. Laura Gómez Gauna pudo datar con certeza este film como el de 1906, gracias al hallazgo de una nota de La Revista Fotográfica Ilustrada del Rio de la Plata, publicada por la casa Lepage, en la que se describe la acción del film en forma coincidente con las escenas del nitrato perteneciente al patrimonio del INET, en especial destacando la presencia del personaje de Cocoliche, pero también describiendo la presencia de los caballos, la carreta, etc. En cuanto al contexto de producción, en esta nota se informa que fue realizada especialmente para representar a la Argentina en la Exposición Universal de Milán de1906, y que el pericón fue dirigido por el actor Alfredo Merlo. 
Por último, el artículo "Mujeres del circo de fines del siglo XIX y principios del siglo XX en Argentina. La vida de carpa entre la libertad y la resistencia" de Camila Losada, a quien también se le concedió la beca Activar Patrimonio, se focaliza en la presencia de la mujer en la historia del circo criollo, que tuvo grandes protagonistas, en especial dos mujeres con unas historias fascinantes, como María Podestá y Rosita de la Plata, dos mujeres muy distintas entre sí en su origen y trayectoria que tuvieron una enorme fama y éxito, que fueron realmente estrellas del circo criollo. Su investigación viene a enriquecer los estudios tanto sobre historia del circo en Argentina como sobre el lugar de la mujer en las artes escénicas desde una perspectiva de género, ambos campos poco abordados hasta ahora. Además de la investigación bibliográfica y documental realizada en el INET, Camila Losada basa su trabajo en los testimonios de diferentes mujeres artistas de circo. Trabaja con dos tipos de testimonios, los provenientes de fuentes secundarias, entre los que destacan especialmente los testimonios recopilados por Beatriz Seibel en sus publicaciones; sin embargo, su gran originalidad radica en los originados en fuentes primarias, las entrevistas personales que ella misma realizó a Olga y Gabriela Videla, madre e hija y directoras actuales de la Escuela de Circo Criollo, fundada por los hermanos Oscar y Jorge Videla en 1982, provenientes de una familia de circo criollo. La importancia de esta Escuela es fundamental para la historia del circo en la Argentina ya que fue la primera del país responsable de la formación de toda una primera generación de artistas de circo.

Como ya dijimos, entre estos trabajos tan diversos en sus contenidos y abordajes, encontramos numerosos puntos de contacto, como la focalización en el estudio del rol de las mujeres en las artes escénicas, tanto en el caso de Blanca Podestá como cabeza de compañía teatral como en el de las mujeres artistas de circo. En el caso del estudio de Camila Losada, se destacan los lazos afectivos que se entrelazan en las compañías de circo, estructuradas en torno a conformaciones familiares y vínculos de parentesco, coincidiendo en numerosos aspectos con las compañías - familias que define Lía Noguera en el caso del teatro, aunque con características propias que devienen de la vida transhumante del circo. Otro punto de contacto es el estudio del pericón, desde una perspectiva musical en el trabajo de Malena Graciosi y desde una perspectiva teatral y cinematográfica en el trabajo de Laura Gómez Gauna. El gran aspecto en común es la referencia a la familia Podestá, que se encuentra presente en todos los trabajos, desde diferentes aspectos: como fundadora de las compañíasfamilia de Pepe, Jerónimo, Pablo y Blanca en el trabajo de Lía Noguera; Pablo y Antonio como autores de música escénica en el trabajo de Malena Graciosi, en el caso del pericón Por María dedicado a María Podestá, mujer artista de circo criollo como las contempladas en el trabajo de Camila Losada; como figuras centrales de la creación escénica de la gauchesca teatral en la que se inserta la danza del pericón nacional y la figura del Cocoliche en el trabajo de Laura Gómez Gauna y por último como los creadores del circo criollo, en el que se estudia la presencia de la mujer en el trabajo de Camila Losada.

Para el INET, estos trabajos implican un enriquecedor aporte, ya que, al ser elaborados en base a la consulta a su acervo documental, permitieron difundir y "activar su patrimonio". Por eso, agradecemos al Ministerio de Cultura por las becas otorgadas a estas mujeres que les brindaron la posiilidad de estudiar los archivos del INET, proponer nuevas miradas al pasado teatral argentino y difundir los materiales tanto en las exposiciones como mediante la publicación en esta revista. 